\title{
Understanding of Dose-Response of Metformin by Using Continuous Glucose Monitoring
}

\author{
Taro Akiyama a, b, Hidetaka Hamasakia, b, Hiroki Adachi ${ }^{\mathrm{a}}$, \\ Hidekatsu Yanaia, c
}

\section{To the Editor}

Metformin is widely used for the treatment of type 2 diabetes; however, the underlying mechanisms for blood glucoselowering remain not fully understood. Metformin is known to reduce hepatic gluconeogenesis which is considered to be the main mechanism of glucose-lowering of metformin [1]. Metformin has been also reported to increase intestinal glucose utilization and reduce food intake, inducing weight reduction and resulting amelioration of insulin resistance $[2,3]$. The activation of AMP-activated protein kinase (AMPK) which is a major cellular regulator of glucose metabolism was reported to be a main mechanism for metformin-mediated beneficial effects on diabetes [4], which was challenged by a recent report [5]. Then, metformin has been suggested to improve glucose metabolism by AMPK-dependent and AMPK-independent mechanisms [6].

Intravenous administration of metformin has been shown to be ineffective [7], and metformin was shown to increase plasma glucagon-like peptide-1 (GLP-1) [8].

Although the mechanisms for metformin-mediated increments in GLP-1 levels remain unknown, it has been hypothesized that metformin stimulates GLP-1 secretion directly and/ or indirectly and prolongs the half-life of GLP-1, and that metformin may potentiate the glucose-lowering effects of GLP-1 by increasing target tissue sensitivity to GLP-1 [9]. Furthermore, metformin has been reported to suppress hepatic glucagon signaling by decreasing production of cyclic AMP [10].

Although various mechanisms have been suggested as metformin-mediated glucose-lowering, it remains unknown which of these mechanisms plays a crucial role at various daily doses of metformin. We performed a continuous glucose monitoring (CGM) in a 47-year-old type 2 diabetic male patient (body height, $171 \mathrm{~cm}$; body weight, $77 \mathrm{~kg}$; BMI, 26.3

Manuscript accepted for publication April 25, 2017

aDepartment of Internal Medicine, National Center for Global Health and Medicine Kohnodai Hospital, Chiba, Japan

${ }^{\mathrm{b}}$ These authors equally contributed to this work.

${ }^{\mathrm{c}}$ Corresponding Author: Hidekatsu Yanai, Department of Internal Medicine, National Center for Global Health and Medicine Kohnodai Hospital, 1-7-1 Kohnodai, Ichikawa, Chiba 272-0034, Japan.

Email: dyanai@hospk.ncgm.go.jp

doi: https://doi.org/10.14740/jem419w $\mathrm{kg} / \mathrm{m}^{2}$ ), referred to our hospital due to poor glucose control. He has been treated by using metformin $(500 \mathrm{mg} /$ day $)$, linagliptin $(5 \mathrm{mg} /$ day) and empagliflozin ( $10 \mathrm{mg} /$ day $)$ for 3 weeks before admission at our outpatient clinic. His HbAlc level was $8.5 \%$ on admission. The treatment for his diabetes was shown in Figure 1.

Results of CGM were shown in Figure 2. CGM showed hyperglycemia late at night and early at morning, suggesting that daily $500-1000 \mathrm{mg}$ of metformin did not induce a sufficient suppression of hepatic gluconeogenesis and/or hepatic glucagon signaling. Daily $1,500 \mathrm{mg}$ of metformin improved hyperglycemia late at night and early at morning, daily 1,500 mg may be needed to suppress hepatic gluconeogenesis and/ or glucagon signaling. However, daily $1,500 \mathrm{mg}$ of metformin could not suppress postprandial hyperglycemia, which was improved by daily $2,000 \mathrm{mg}$ of metformin, indicating that daily $2,000 \mathrm{mg}$ may be needed for an increment of GLP-1 secretion and/or activity.

We have to mention the limitation of our observation. First, this report is the observation of only one case. Second, other hypoglycemic agents may have an influence on the study results.

In conclusion, our observation of dose-response of metformin by using CGM may propose the glucose-lowering mechanism due to metformin varies depending on the dose.

\section{Conflicts of Interests}

The authors declare that they have no conflicts of interest concerning this article.

\section{References}

1. DeFronzo RA, Barzilai N, Simonson DC. Mechanism of metformin action in obese and lean noninsulin-dependent diabetic subjects. J Clin Endocrinol Metab. 1991;73(6):1294-1301.

2. Penicaud L, Hitier Y, Ferre P, Girard J. Hypoglycaemic effect of metformin in genetically obese (fa/fa) rats results from an increased utilization of blood glucose by intestine. Biochem J. 1989;262(3):881-885.

3. Lee A, Morley JE. Metformin decreases food consumption and induces weight loss in subjects with obesity with type II non-insulin-dependent diabetes. Obes Res. 


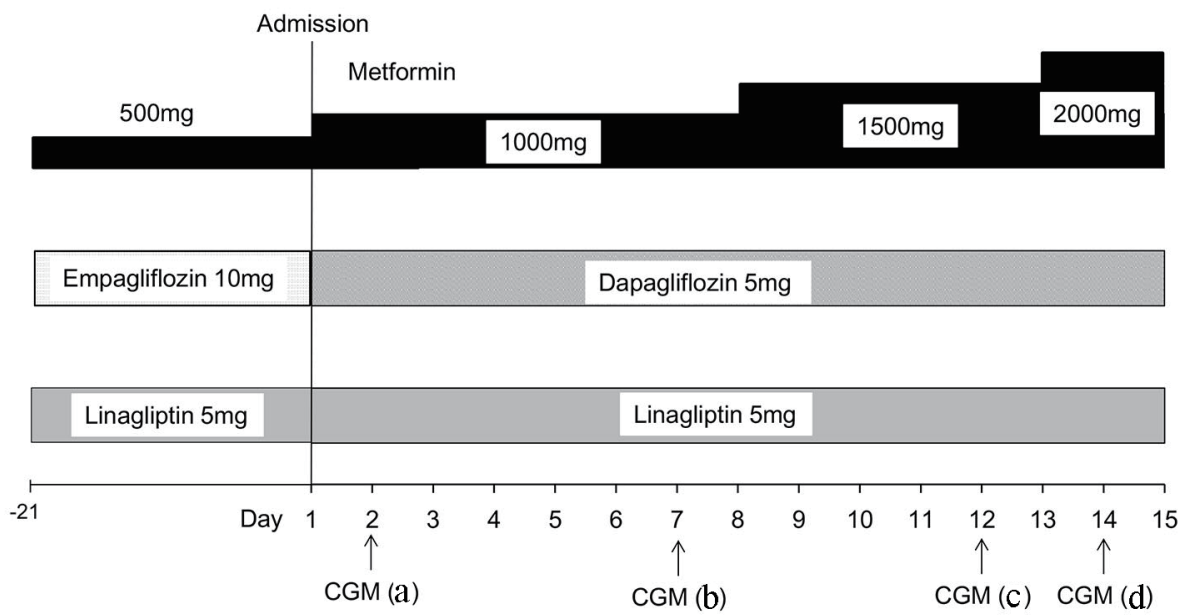

Figure 1. Treatment for type 2 diabetes before and after admission. Continuous glucose monitoring (CGM) a-d correspond with a-d in Figure 2.

Day 2, treated by metformin $1000 \mathrm{mg} /$ day (from Day 1), linagliptin $5 \mathrm{mg} /$ day, dapaglifloizin $5 \mathrm{mg} /$ day, $1600 \mathrm{kcal} /$ day, no exercise

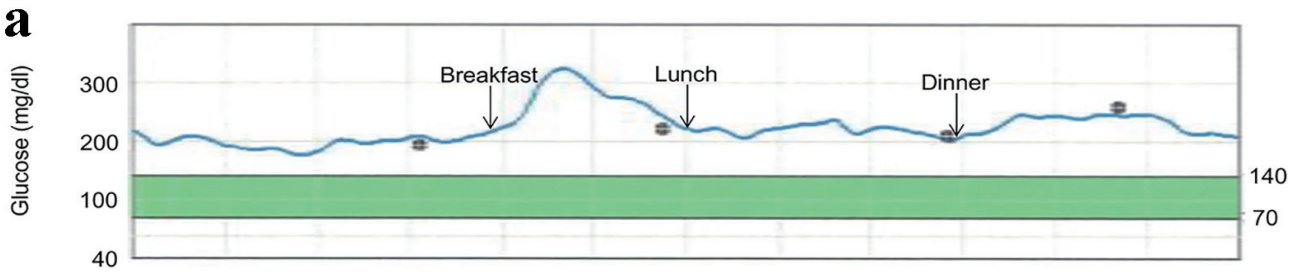

Day 7 , treated by metformin $1000 \mathrm{mg} /$ day, linagliptin $5 \mathrm{mg} /$ day, dapaglifloizin $5 \mathrm{mg} /$ day, $1600 \mathrm{kcal} /$ day, no exercise

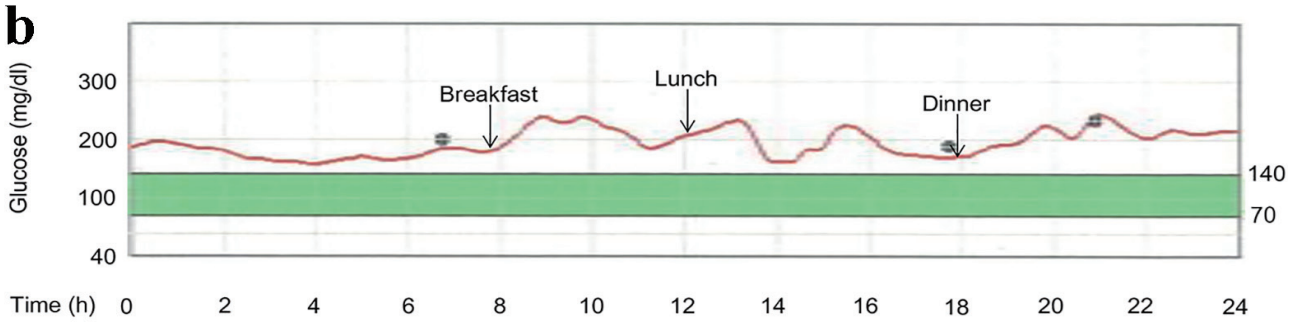

Day 12 , treated by metformin $1500 \mathrm{mg} /$ day (from Day 8), linagliptin $5 \mathrm{mg} /$ day, dapaglifloizin $5 \mathrm{mg} /$ day, $1600 \mathrm{kcal} /$ day, no exercise

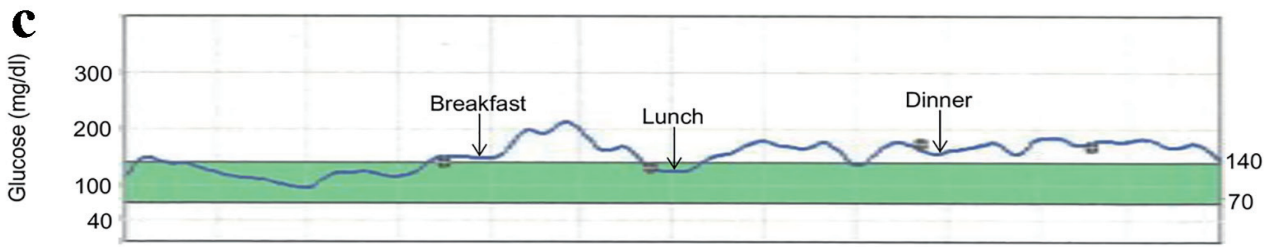

Day 14, treated by metformin $2000 \mathrm{mg} /$ day (from Day 13), linagliptin $5 \mathrm{mg} /$ day, dapaglifloizin $5 \mathrm{mg} /$ day, $1600 \mathrm{kcal} /$ day, no exercise

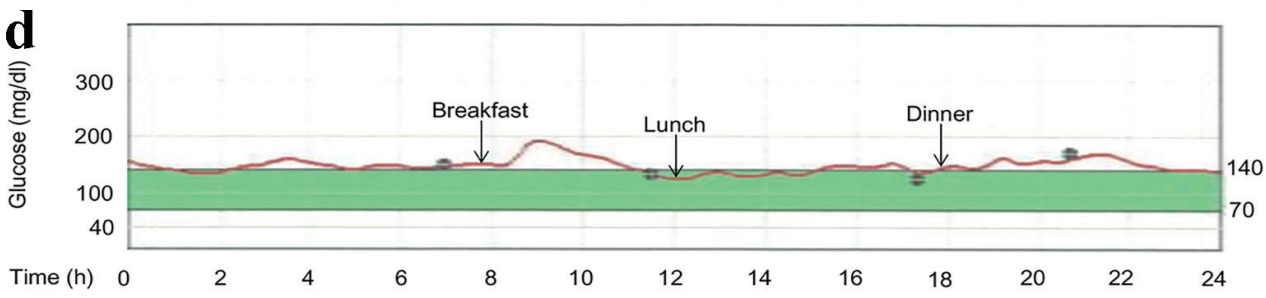

Figure 2. Continuous glucose monitoring (CGM) showing dose-response of metformin. 
1998;6(1):47-53.

4. Zhou G, Myers R, Li Y, Chen Y, Shen X, Fenyk-Melody $\mathrm{J}, \mathrm{Wu} \mathrm{M}$, et al. Role of AMP-activated protein kinase in mechanism of metformin action. J Clin Invest. 2001;108(8):1167-1174.

5. Foretz M, Hebrard S, Leclerc J, Zarrinpashneh E, Soty M, Mithieux G, Sakamoto K, et al. Metformin inhibits hepatic gluconeogenesis in mice independently of the LKB1/ AMPK pathway via a decrease in hepatic energy state. $\mathrm{J}$ Clin Invest. 2010;120(7):2355-2369.

6. Foretz M, Guigas B, Bertrand L, Pollak M, Viollet B. Metformin: from mechanisms of action to therapies. Cell Metab. 2014;20(6):953-966.

7. Sum CF, Webster JM, Johnson AB, Catalano C, Cooper $\mathrm{BG}$, Taylor R. The effect of intravenous metformin on glucose metabolism during hyperglycaemia in type 2 diabetes. Diabet Med. 1992;9(1):61-65.

8. Mannucci E, Tesi F, Bardini G, Ognibene A, Petracca MG, Ciani S, Pezzatini A, et al. Effects of metformin on glucagon-like peptide-1 levels in obese patients with and without Type 2 diabetes. Diabetes Nutr Metab. 2004;17(6):336-342.

9. Bahne E, Hansen M, Bronden A, Sonne DP, Vilsboll T, Knop FK. Involvement of glucagon-like peptide-1 in the glucose-lowering effect of metformin. Diabetes Obes Metab. 2016;18(10):955-961.

10. Miller RA, Chu Q, Xie J, Foretz M, Viollet B, Birnbaum MJ. Biguanides suppress hepatic glucagon signalling by decreasing production of cyclic AMP. Nature. 2013;494(7436):256-260. 